\title{
Operation and Maintenance of Secondary Reformer - Lessons from Plant experiences
}

\author{
Sk Shafi Ahmed ${ }^{a^{*}}$ and Md. Enamul Haque ${ }^{b}$

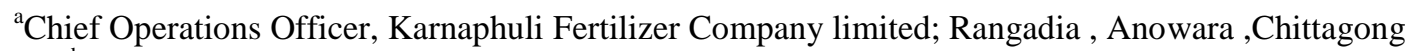 \\ ${ }^{\mathrm{b}}$ General Manager Karnaphuli Fertilizer Company limited; Rangadia , Anowara ,Chittagong
}

KARNAPHULI FERTILIZER COMPANY (KAFCO) is the biggest ammonia-urea complex in Bangladesh. The Complex has two Plants - Ammonia and Urea having a capacity to produce 2000 MTPD granular urea and 1600 MTPD anhydrous ammonia respectively. One of the important equipment of its Ammonia production facility is Secondary Reformer operating at about 1400C. It is a catalytic reactor having refractory and castables inside with a special hydrogen burner. In 1997; there was a serious failure of Secondary Reformer in Jamuna Fertilizer Plant of Bangladesh Chemical Industries Corporation (BCIC) causing a total plant shutdown of about 7 months and huge business loss. To avoid such catastrophic failure; KAFCO analyzed the reasons and developed measures to avoid the breakdown. Its Secondary Reformer is operating successfully during the last 18 years. These articles describe all of these and recommend a healthy life program for Secondary Reformer.

\section{INTRODUCTION}

The Jamuna Fertilizer Company Ltd (JFCL) has an ammonia Plant having production capacity of 1078 MTPD. On August 25, 2001 late morning; during plant operation; the secondary reformer shell of Jamuna Fertilizer bulged out below top cone at an area of about one squire meter. A horizontal crack about $500 \mathrm{~mm}$ with a clean red hot spot was also developed on the welding joint in the bulged area. The plant had an emergency shutdown. It took about 7 months to repair the reactor and restart production. That was a huge loss to the company; and following is the summary of what happened:

\section{$\underline{\text { Nature of Failure: }}$}

Failure Time: $\quad 06: 45 \mathrm{hr}$ in the morning

Bulging Area: $1400 \mathrm{~mm} \times 600 \mathrm{~mm}$

Bulged height: $250 \mathrm{~mm}(\max )$

Bulged area bears a clear hot spot mark

Crack developed: Horizontal crack in the bulged area of the welding point

Crack dimension $700 \mathrm{~mm} \times 50 \mathrm{~mm}$

\section{Refractory conditions:}

The refractory on top conical part in the bulged area has been shifted outward (toward burner); appeared a number of long cracks in and around

Damaged area ranging in width from $10-20 \mathrm{~mm}$.

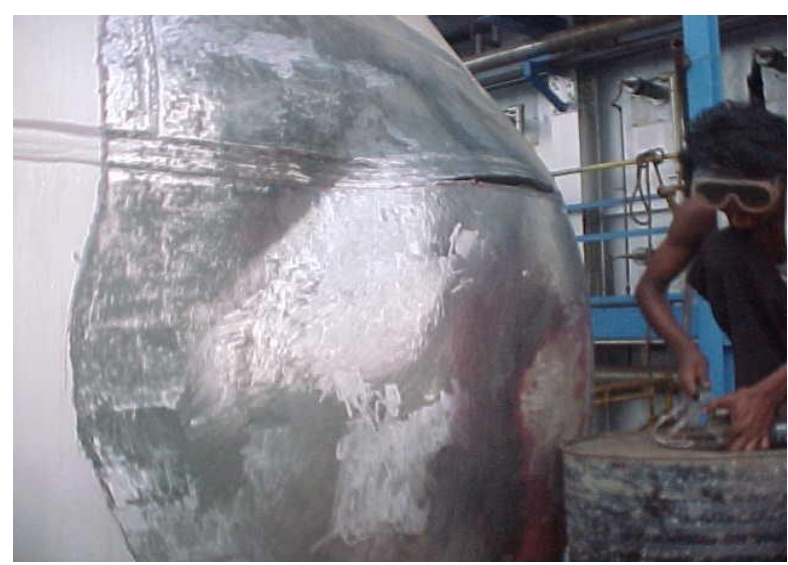

Figure 1: Bulging of 2RF Shell

\section{REASONS FOR FALURE -JFCL}

The shell was over heated above 350C.; and a bulging effect due to huge gas pressure on the conical portion happened. The process gas of $1300 \mathrm{C}$ has touched the inner metallic surface of the shell in the conical portion. Very big and long cracks have developed within the castables during plant operation and the castables have fallen in some areas due to cutting of the anchors. The anchors bond the castables with the metal surface. The big crack developed within the castables has allowed process gas to reach the metal shell and overheated the Carbon steel metals. 


\section{SECONDARY REFORMER}

The 2 RF consists of

- A cylindrical Carbon Steel vessel; C;1/2 Mo steel

- One $\mathrm{H}_{2}$ Burner inside

- Conical portion with castables having locked with anchors

- Castables and Refractory -locally casted and with 2 or 3 layers

- Bed with Tyles ;alumna lumps and catalysts

- Bottom Arch

- Water Jacket- in some design

The temperature inside the reactor works about $1400 \mathrm{C}$ without harming the vessel. The vessel has bricks and castables inside to protect the shell from overheat. It is filled with several hole cylindrical type catalyst. The catalyst bed is rested on a brick arch in the bottom. The combustion of Hydrogen with oxygen gives high temperature at the top of the catalyst bed. The reforming reaction of methane lowers the temperature during passage of the gas mixture through catalyst bed and at the exit of the reformer, the temperature reaches about $1000 \mathrm{C}$.

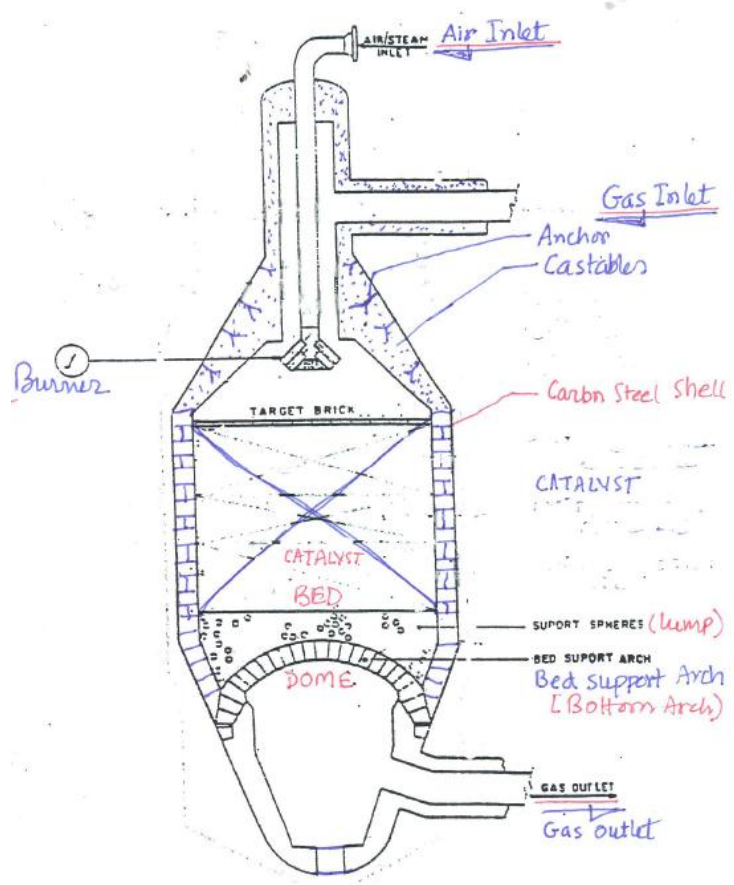

Figure Secondary reformer.

Figure 2. Secondary Reformer
Details are:

\section{1: Castables and Refractory}

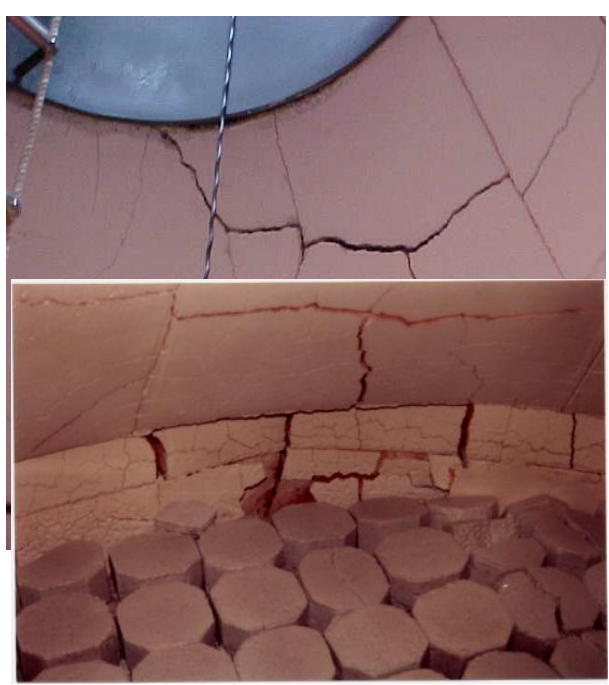

Figure 4: Castables inside 2RF

\section{2: $\quad$ Conical Portion}

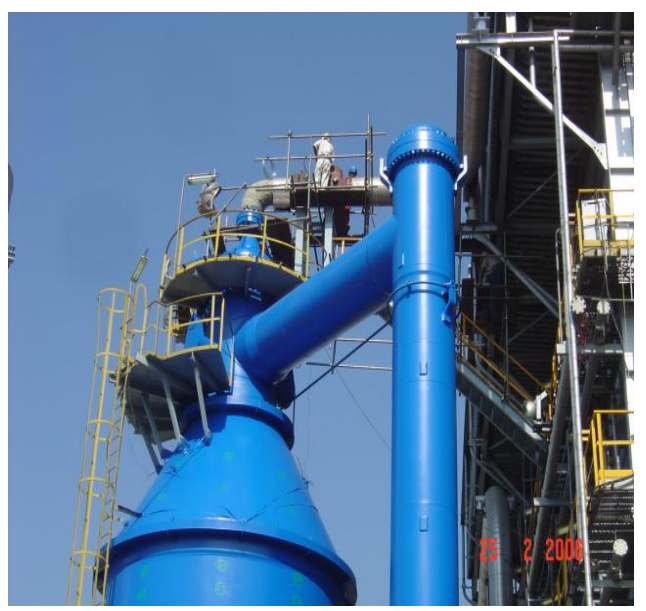

Figure 5 : Conical Portion of the 2RF

\section{3: $\quad$ Anchors inside the Castables}

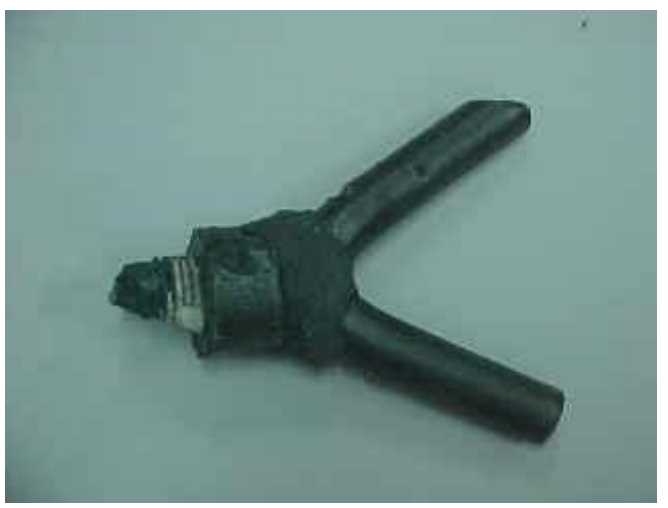

Figure 6 : Anchors 


\section{4: $\quad$ Burner}

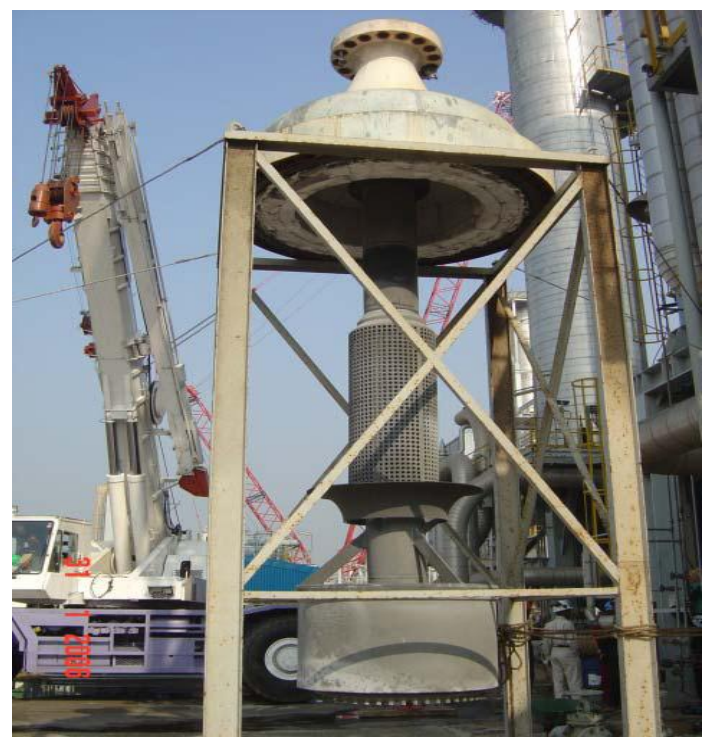

Figure 7: $\mathrm{H}_{2}$ Burner within the $2 \mathrm{RF}$

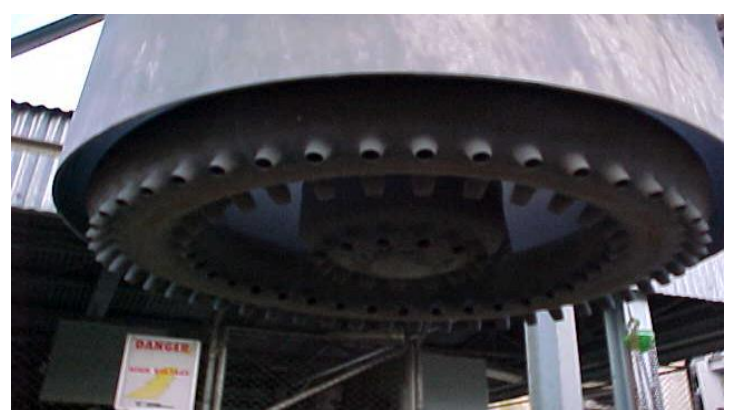

Figure 8: Tip of the Burners

\section{5: $\quad$ Bottom Arch}

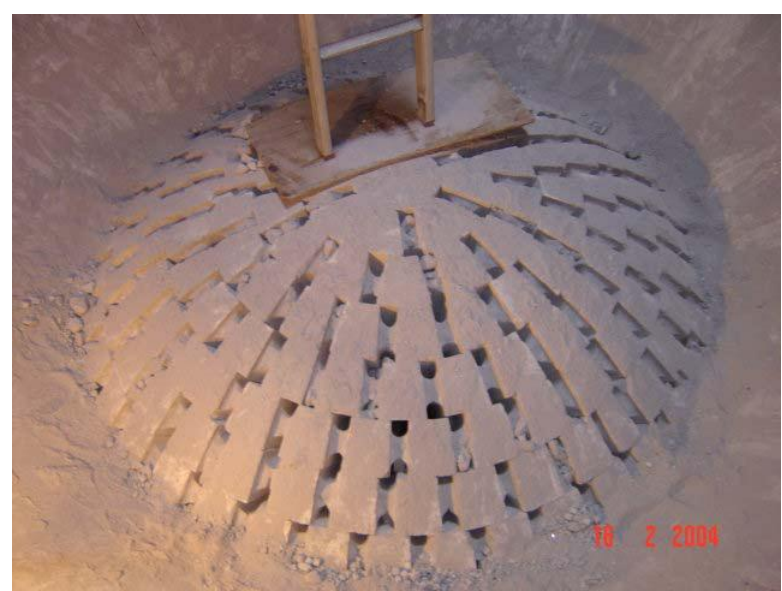

Figure 9: Bottom Dome within 2RF

3.6: Catalyst

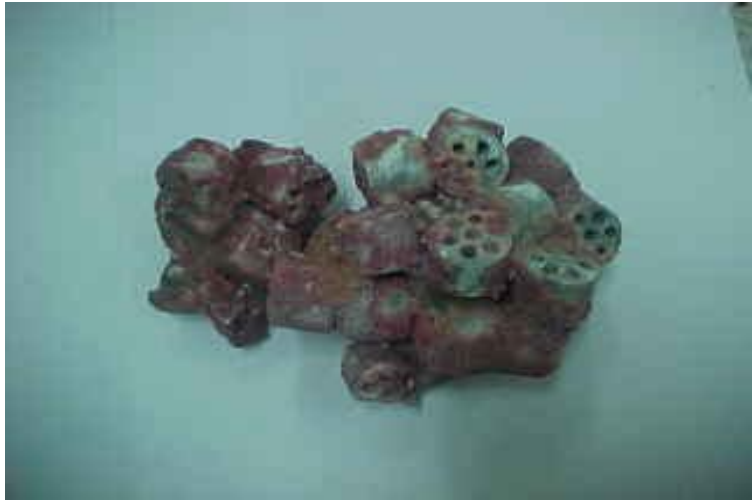

Figure 10: Catalyst with lump

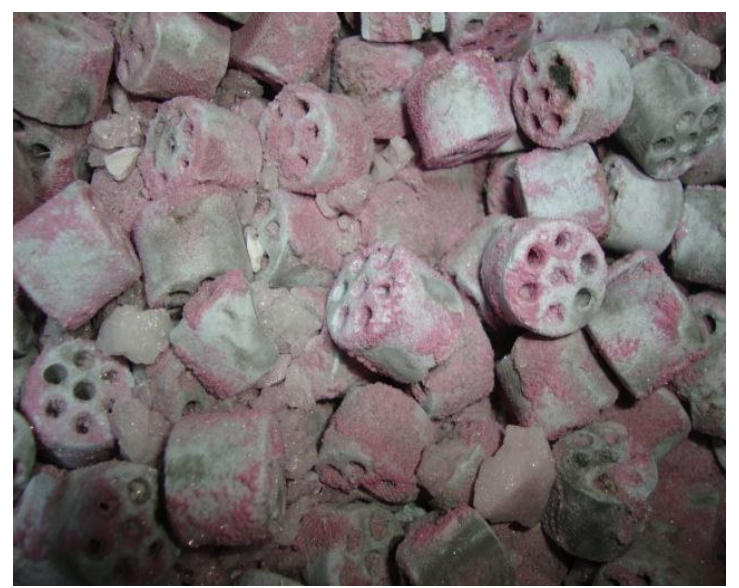

Figure 11: Catalyst with Dust and ruby colour

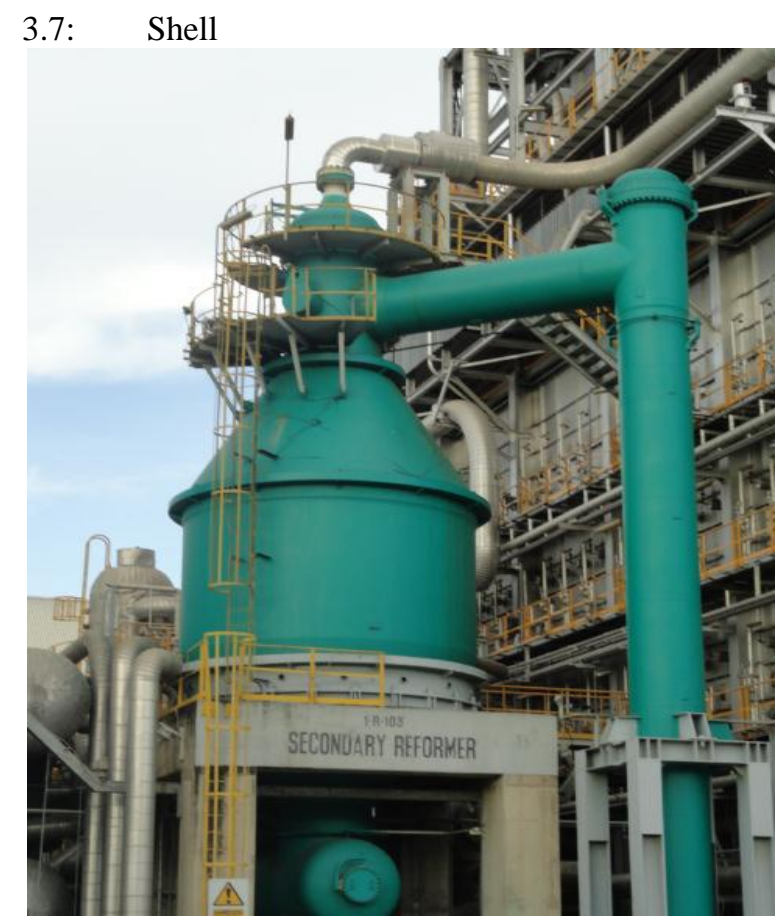

Figure 12 Metallic Shell of $2 \mathrm{RF}$ with temperature sensitive paint 


\section{Monitoring during Plant Operation}

During plant operation; $2 \mathrm{RF}$ is monitored from outside by the shell temperature; outlet process gas temperature; Pressure drop of the Converter and Methane content. In addition to a special temperature sensitive paint is used to understand the overheat. Now a day's thermography is also used to see the temperature profile on the shell skin.

Physical inspection of the Surface by seeing the colour a tool. The Plant installed 8 no of thermocouples on conical portion on the shell for monitoring.; temperature range varying from $50^{\circ} \mathrm{C}$ to $110^{\circ} \mathrm{C}$.

\section{5: INSPECTION}

\section{Activities during Turnaround}

The reactor is Inspected every Turnaround happening after two years interval. Detail Inspection is carried out physically with some measurement

The sensitive parts to be inspected are:

$$
\begin{aligned}
& \text { Burner } \\
& \text { Conical Portion } \\
& \text { Catalyst dust } \\
& \text { Bottom Arch and gas outlet } \\
& \text { Painting of Shell }
\end{aligned}
$$

\section{Burner :}

\section{Visual Inspection}

- Check for cracks especially in welds

- Burner tips - deformation or crack.

-Top ring of the refractory box - Deformation

-Refractory wool -Condition and missing.

-Refractory work- required and the quantity

-Plate replacement and Material.

-Refractory in the dome shows no severe damage

Dye penetration test (DPT):

The DPT of all welds of the Burner.

\section{Refractory and castables - Inside 2RF}

Condition of top Protection bricks of the Bed - Crack and displacement

Catalyst under the bricks - Colour especially ruby formation Catalyst dust -Presence and amount Ruby formation of catalyst -- characteristics and location - e.g center and peripheral areas

Under the top layer catalyst bed - lots of catalyst dust was and ruby formed catalyst presence.

\section{Conical Portion}

Condition of Castables - Sound from rubber hammer Cracks; progress of cracks and propagation

\section{Bottom Arch}

General Condition and crack

\section{Shell Condition}

Painting condition; Check of general corrosion; thickness and weld check

High temperature Paint quality is very important

\section{Measurement of Catalyst Dust:}

Catalyst is carefully monitored during all or alternate Turnarounds (TA). All broken catalyst; dust and agglomerated catalyst is removed during this period. The whole bed in unloaded to do the job. The catalyst unloading help inspection of the bottom arch.

The following Table illustrates some example of dust removal from a Plant. The catalyst replenishment amount is from 15 to $30 \%$. of the total bed volume.

Table-1: Dust and Broken Catalyst Removal

\begin{tabular}{|c|c|c|}
\hline $\begin{array}{c}\text { Turn } \\
\text { Around }\end{array}$ & $\begin{array}{c}\text { Catalyst } \\
\text { Replenished } \\
\text { wt\% }\end{array}$ & $\begin{array}{c}\text { Dust \& } \\
\text { broken } \\
\text { catalyst, } \\
\text { MT }\end{array}$ \\
\hline TA-0202 & 16.44 & 2 \\
\hline TA-2004 & 24.29 & 2.2 \\
\hline TA-2006 & 25.84 & 1.2 \\
\hline TA-2008 & 28.61 & 0.2 \\
\hline
\end{tabular}

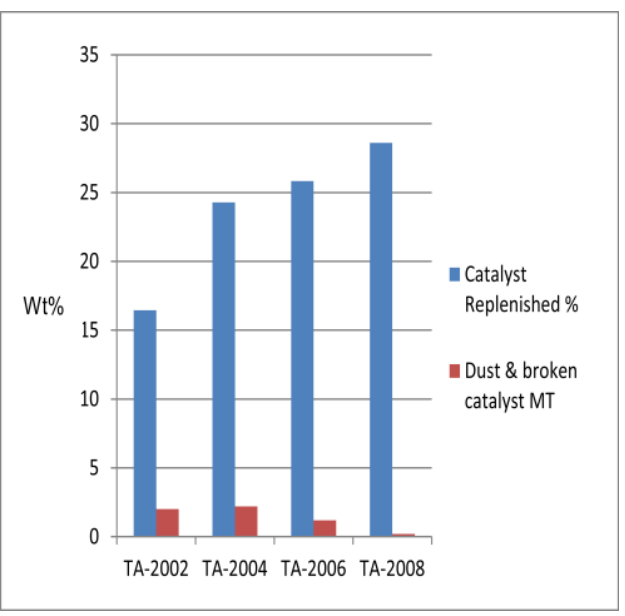

Figure 13 : Comparing Dust and Total catalyst 


\section{CONCLUSION}

Caring $2 \mathrm{RF}$ is very important for plant production. This means caring and regular inspection of catalyst, refractory and castables; anchor, bottom arch; Burners and anchor within the castables etc during Plant operation and annual Turnarounds

KAFCO experiences periodic and regular Inspection of the Castables, Burner; Brick; removal of the Catalyst dust from the bed; and continuous monitoring the shell temperature and bed pressure drop. These measures can make the Secondary Reactor healthy with minimum risk for operation in its life cycle

\section{RECOMMENDATION}

The $2 \mathrm{RF}$ is very important Reactor for Ammonia plant operation. The equipment needs care and regular monitoring during plant operation and Turnaround for a sustainable and reliable plant operation. The procedure followed in KAFCO Plant is a proven record of a health Secondary Reformer supporting Plant life cycle operation.

\section{REFERENCES}

[1] Unpublished Plant Records - Jamuna Fertilizer Company limited, Tarakandi Jamalpur.

[2] Experiences from Plant Operation and Turnaround-Personal record. 